\title{
Joseph Black (1728-1799) \\ und die Anfänge chemischer Experimentalforschung in Biologie und Medizin*
}

\author{
Von Heinrich Buess
}

\author{
Inhalt \\ 1. Neuere spezielle Arbeiten über die Anfänge der Gas-Chemie \\ 2. Zur Entwicklung der Gas-Chemie bis $\mathbf{1 7 9 0}$ \\ 3. Joseph Blacks Persönlichkeit \\ 4. Heuristische und experimentelle Prinzipien in Blacks chemischer Analyse \\ 5. Die biologische Wendung in Blacks Chemie \\ 6. Die Ausweitung der chemischen Forschung in der Biologie (Macbride, Henry)
}

\begin{abstract}
«Um die Geschichte der Wissenschaften aufzuklären, um den Gang derselben genau kennenzulernen, pflegt man sich sorgfältig nach ihren ersten Anfängen zu erkundigen; man bemüht sich zu forschen: wer zuerst irgendeinem Gegenstand seine Aufmerksamkeit zugewendet, wie er sich dabei benommen, wo und zu welcher Zeit man zuerst gewisse Erscheinungen in Betracht gezogen, dergestalt, daß von Gedanken neue Ansichten sich hervorgetan, welche, durch Anwendung allgemein bestätigt, endlich die Epoche bezeichnen, worin das, was wir eine Entdeckung, eine Erfindung nennen, unzweifelhaft zutage kommt - eine Erörterung, welche den mannigfachsten Anlaß gibt, die menschlichen Geisteskräfte zu kennen und zu schätzen.» J.W.GoEthe, Geschichte meines botanischen Studiums (1817). (Artemis-Ausgabe, Bd.17, Zürich 1952, S.62.)
\end{abstract}

Im allgemeinen wird in der Geschichte der medizinischen Biologie angenommen, daß durch den Schöpfer der modernen Chemie, A.L. Lavoisier (1743-1794), die chemischen Methoden in die experimentelle Physiologie eingeführt worden seien. In der breiten Wirkung auf die späteren Forscher muß man diesem Axiom zustimmen. Bei genauerem Zusehen wird der kritische Interpret indessen zugeben müssen, daß - sowenig erst seit Lavoisier das quantitative Denken in der Chemie besteht - der geniale französische

* Für die Überlassung des Klischees zu Abb. 1 sei der Redaktion des Ciba-Symposiums bestens gedankt. 
Analytiker an recht wertvolle Vorarbeiten anknüpfen konnte. Hatte der junge Naturforscher diese Tatsache mehr oder weniger freimütig zugegeben, so scheint der von seinen Erfolgen begeisterte Generalpächter doch allzu leicht übersehen zu haben, wieviel er andern, und wieviel er vor allem dem schottischen Arzt Joseph Black (1728-1799) verdankte.

Es entspricht daher einem Bedürfnis nach historischer Gerechtigkeit, wenn der Anlaß der vor zweihundert Jahren veröffentlichten Abhandlung dieses schottischen Chemikers dazu benützt wird, um von medizinischhistorischer Seite einmal auf diese Zusammenhänge aufmerksam zu machen. Inwieweit die Verdienste Blacks in neuerer Zeit bereits gewürdigt worden sind, mag der am Schluß angeführte Überblick über die vorwiegend fremdsprachige Literatur dartun, wobei schon hier betont sei, daß uns die grundlegende Biographie (1918) Blacks aus der Feder von Sir William Ramsay trotz allen Bemühungen nicht zur Verfügung stand.

\section{Neuere spezielle Arbeiten über die Anfänge der Gas-Chemie}

Ohne irgendwelchen Anspruch auf Vollständigkeit sei nachstehend auf einige besonders aufschlußreiche Studien zur Geschichte der pneumatischen Chemie im 18. Jahrhundert hingewiesen. Den Anfang in dieser Richtung macht ohne Zweifel der große Lavoisier selber, indem er in den Opuscules physiques et chimiques (1774), einer seiner ersten klassischen Abhandlungen, auf die älteren Versuche über «die elastischen Emanationen» bei der Verbrennung, Gärung und Efferveszenz ausführlich eingeht. Wir werden in späteren Abschnitten auf diesen «Précis historique» zurückkommen. Hier sei nur zum (7.) Kapitel über Black allgemein festgestellt, daß Lavoisier ausschließlich die Arbeit des Jahres 1756 ins Auge gefaßt, also die späteren biologischen Experimente Blacks völlig mit Stillschweigen übergangen hat, obgleich er ohne Zweifel darum gewußt haben muß. Vielmehr scheint Lavoisier diese wesentliche Ausweitung der chemischen Experimente sozusagen ausschließlich auf das Konto von David Macbride (vgl. unten) zu setzen, wird also seinem bedeutendsten Vorläufer auch hierin zu wenig gerecht. Hätte er doch gerade aus den objektiven Darlegungen des letzteren erkennen können, wie sehr dieser dem damaligen Professor der Anatomie in Glasgow verpflichtet war.

Diese Unterlassung Lavoisiers scheint sich durch die späteren chemiegeschichtlichen Werke weitergepflanzt zu haben (Hermann Kopp, Ernst von Meyer u.a.). Aber auch die wegweisende biographische Studie Ramsays 
aus dem Jahre 1909 enthält von Blacks wertvollen späteren Versuchen kein Wort, und Max Speter verfällt in seinem Beitrag (1929) zum Werk Das Buch der großen Chemiker demselben Fehler wie seine Vorgänger, alles was an physiologischen Experimenten vorhanden war, den früheren oder späteren Forschern, nur eben nicht Black, zuzuschreiben.

Überhaupt kann den Chemiehistorikern der Vorwurf nicht erspart werden, daß sie aus einer Scheuchleder-Perspektive heraus alles irgendwie zur Biologie Gehörende aus ihren Darstellungen verbannt haben. Dies gilt, soweit ich sehe, auch für die äußerst aktive Französin Hélène Metzger, welche mehrere ausgezeichnete Abhandlungen zur Chemie und Physik des 17. und 18. Jahrhunderts gewidmet hat. Ich denke hier vor allem an die tiefgründige gesamthafte Veröffentlichung Newton, Stahl, Boerhaave et la doctrine chimique (Paris 1930), die sich allzu ausschließlich mit den drei großen Gelehrten befaßt, ohne einen Blick über das engere Fachgebiet hinaus zu tun.

Die letzten Jahre haben uns einige wertvolle Schriften des Londoner Dozenten Douglas MaKie beschert. Außer seinem wohl als abschließend zu beurteilenden Buch über die Geschichte der Entdeckung der latenten Wärme, welche die Verdienste Blacks und der Skandinavier, besonders WiLcKes sorgfältig gegeneinander abwägt, sind sein Aufsatz über СосHRANES Vorlesungsnotizen von Blacks Vorlesungen $(1936)^{1}$ und die kürzlich erschienene Biographie über Lavoisier zu nennen. In beiden Texten wird der Auswertung von Blacks Experimenten über «fixe Luft» in die physiologische Ebene weitgehend Rechnung getragen, indessen ohne besonderen Kommentar, der allerdings den Rahmen einer chemiegeschichtlichen Untersuchung wohl gesprengt hätte. In den lokalhistorischen Zusammenhang gehört auch die Zusammenstellung von James Kendall über die Anfänge der chemischen Gesellschaft von Edinburgh mit der handgeschriebenen Liste Blacks von deren Mitgliedern, in der dem Verhältnis zwischen Black und Lavoisier besondere Beachtung geschenkt wird.

Die letzten hier zu würdigenden Arbeiten entstammen dem verdienten amerikanischen Kreis der Chemiehistorie, indem Henri Guerlac zeigt, daß die Übersetzungen des Werkes von Stephen Hales den ersten Kontakt des französischen Forschers mit den Vorarbeiten der britischen Pneumatiker bilden. Und sein Schüler KERKER, ebenfalls von der Cornell

1 Mr. F.N.L.Poynter von der "Wellcome Historical Medical Library" in London danke ich auch hier für die Vermittlung einer Photokopie dieser Arbeit. 
University, befaßt sich schließlich mit dem hervorragenden Beitrag Hermann BoerhaAves (1668-1738) zur Chemie der Gase (1955), ohne daß ein bestimmter Einfluß auf Black nachgewiesen werden konnte.

\section{Zur Entwicklung der Gas-Chemie bis 1750}

Bevor auf die bahnbrechende Entdeckung Blacks kurz eingegangen wird, ist es notwendig, zuerst die ersten Schritte in der Erforschung der gasförmigen Stoffe vor seiner Zeit kennenzulernen. Von besonderem Interesse dürfte es hier sein, die Begründer dieser Lehre, also Black und Lavoisier, selber zum Worte kommen zu lassen.

Die frühesten, noch tappenden Versuche stellte bekanntlich J.B. vaN Helmont (1577-1644) an, dessen Abhandlung De flatibus auch in die recht inhomogene Sammlung seiner Schriften Aufnahme gefunden hat. Black ging es in seinen eigenen Experimenten darum (Vorlesungen, deutsch, Bd. II, S. 382), die Aussage des «Faust des 17. Jahrhunderts» (HAEser) nachzuprüfen, daß dessen «Gas sylvestre» den tödlichen Dunst der brennenden Kohle darstelle. Viel ausführlicher geht der französische Forscher auf seinen ebenso vielseitigen flämischen Vorläufer ein, indem er über Black hinaus das Entstehen dieses Gases auch bei der Gärung (Wein usw.), der Efferveszenz durch Säuren und in der Hundsgrotte von Neapel aufführt. Auch die Entstehung des Gases bei der Verdauung und bei der Leichenverwesung, die Helmont in weit vorausschauender Konzeption erfaßt hatte, werden besonders gewürdigt. Auch in der Annahme, daß dieses Gas von der Atemluft verschieden sei und aus einer Kombination einer feinen Säure mit einem flüchtigen Alkali bestehe, erweist sich der Brüsseler Naturforscher als würdiger Vorläufer Blacks. Daß die Stelle in seiner Abhandlung De lithiasi (Kap. IV, Nr. 7) einen unmittelbaren Anknüpfungspunkt für die Untersuchungen in Glasgow hätte bilden können, sei abschließend festgehalten.

Es ist eigenartig, festzustellen, daß der, abgesehen von BoyLE, den späteren Erforschern der Gase am meisten verwandte JoHN MAYow (1645 bis 1679) für Black irgendwie verschlossen blieb, indem dieser seine «dunkle geheimnisvolle Sprache » beanstandete, und daß Lavoisier von den Schriften Mayows überhaupt nichts wußte. Was Mayows Physiologie der Atmung betrifft, auf die früher ausführlich verwiesen wurde ${ }^{2}$, so hätte gerade der

2 Ciba Zeitschrift 8 (1943), 3200-3, mit zwei Abbildungen. 
junge Schüler Boyles mit seinem «nitrum aëris» den Späteren manche Schwierigkeiten ersparen können.

Breiten Raum nehmen sowohl bei Black und Macbride wie bei Lavoisier die teilweise genialen Versuche des englischen Landpfarrers Stephen Hales (1677-1761) ein.

Tatsächlich brachten seine ausführlichen Versuchsprotokolle, die in den Statical Essays ..., also A Specimen of an Attempt to Analyse the Air... (3. Aufl., London 1738) enthalten sind, durch die Veröffentlichung neuer Apparate, vor allem einen wesentlichen methodischen Fortschritt, dem Black und die Späteren viel verdanken. Es ist nicht möglich, hier auf die Gesamtheit von Hales' sinnreichen Experimenten einzugehen. Es seien lediglich einige Stellen herausgegriffen, die auf die Atmungsphysiologie, d.h. i.e.S. zum Endprodukt des respiratorischen Stoffwechsels näheren Bezug nehmen.

Im ganzen ist die herkömmliche Ansicht (Lavoisier, a.o.O., S. 452 ff.) zutreffend, daß Hales nur die Mengenverhältnisse der Gase berücksichtigt habe, ohne deren verschiedenen Charakter zu erkennen, so etwa, wenn er (I, 169 ff.) die Reduktion der Luftmenge bei der Verbrennung bestimmt. Auch dort, wo er im Anschluß an Mayow bei der Ratte das Volumen der Atemwege bestimmt, ist nur vom "Vivifying spirit» die Rede (I, 236ff., 277). Unmittelbaren Einfluß gewann er auf Black durch seine Versuche mit «diaphragms» aus verschiedenen Stoffen, die er mit Meersalz u.a. befeuchtete, deren Gewichtszunahme er bestimmte (I, 264 ff.) sowie durch die Destillation von Kalksteinen (II, 194 ff.), die zu einer Gewichts-Verminderung, ja sogar Auflösung führte. Die Untersuchungen der Atmungsluft in geschlossenen Räumen, die dadurch «unfit for respiration» wurde (II, 320 f.), führten den ingeniösen Mann bekanntlich zu seinen hygienischen Vorschlägen (Anwendung von Essig usw. zur Verbesserung), die auch in der englischen Marine eine gewisse Bedeutung erlangten. Doch erlaubten ihm auch hier die damaligen chemischen Kenntnisse kein tieferes Eindringen in die Materie. Aber gerade auf Lavoisier übten diese systematischen quantitativen Überlegungen ohne Zweifel eine größere Wirkung, als dieser vielleicht selber wahrhaben wollte. Späteren Forschern, wie Ramsay (S. 441), fiel es indessen nicht schwer, in den verschiedenen entwickelten Gasarten «unreinen Wasserstoff, Sumpfgas, Kohlensäuregas und Sauerstoff » zu erkennen.

Ungefähr zu gleicher Zeit wie Hales' berühmte Schrift erschienen die Elementa chemiae (1732) des großen Hermann Boerhaave, der zwar in der 
Erstlingsschrift Blacks nirgends namentlich genannt ist, aber ohne Zweifel dessen Denken - auch im medizinischen Bereich - entscheidend beeinflußt hat. Wie man sich diese Beziehungen vorzustellen hat, ist von Kerker im dritten Teil seiner Arbeit gezeigt worden (Boerhaave - Plummer - Cullen Black). Es ist bereits von Lavoisier, Hélène Metzger und Kerker betont worden, wie vieles im Werk des holländischen Enzyklopädisten aus den physikalischen Lehren jener Zeit zu verstehen ist. Auch waren seine mit der Vakuumpumpe Boyles angestellten Versuche, die in ihrer Anordnung großenteils auf Hales zurückgehen, zum größten Teil von physikalischmolekularen Fragestellungen vor allem im Sinne Newtons diktiert, die uns heute schwer verständlich sind (elastische Partikel usw.). Daneben aber finden sich Andeutungen chemisch-analytischer Überlegungen, so besonders dort (Bd. I, S. 433), wo er in neutralen Salzen oder in den «Krebsaugen» durch Zusammenbringen mit Säure «eine wunderbare elastische Luft» entbinden konnte. Diese im Vakuum quantitativ ausgeführten Experimente führten ihn ähnlich wie Hales zum Schluß, daß das freigewordene Gas, das auch im organischen Gewebe schon Hales nachgewiesen hatte, etwas anderes als gewöhnliche Luft sein müsse. Ja, durch diese gasometrischen Bestimmungen fühlte er sich sogar an das «Gas sylvestre» van Helmonts erinnert. Als Arzt erklärte er sich durch diesen Gasgehalt das feste Zusammenhalten der festen Körper. Wir werden sehen, daß Boerhaaves von Hales übernommene Vorstellung der Kohärenz der festen Teile durch die elastischen Partikel in seinem Schüler Albrecht HALLER (1708-1777) weiterlebte und dann zu einem der Schlüsselpunkte der späteren schottischen biochemischen Schule wurde. Auf diese Weise bildet Boerhaave das Bindeglied zwischen Boyle-Mayow-Hales und BlackMacbride-Lavoisier. Nur sollte die weitere Entwicklung zu einer schrittweisen Elimination der älteren atomistisch-molekularen Denkweise führen, von der bei Lavoisier nur noch einzelne Spuren zu finden sind.

\section{Joseph Blacks Persönlichkeit}

Vor uns liegt der zweite Band der Essays and Observations, Physical and Literary, Read before a Society in Edinburgh and Published by Them, der 1756 bei den Universitätsdruckern G. Hamilton und J. Balfour herausgekommen ist. Dieses erst später fortgesetzte Periodikum aus dem Besitz der Universitätsbibliothek Basel enthält in den ersten beiden Jahrgängen je etwa dreißig Abhandlungen von außerordentlich vielseitigem Inhalt, auf 
die hier nicht eingegangen sei. Unter ihnen befindet sich nun aber als «Art. VIII» (S. 157-225) auch die Arbeit von «Joseph Black, M.D.», die am 5. Juni 1755 offenbar nur teilweise mündlich vorgetragen worden war.

Bevor wir auf diese Studie kurz und nur grundsätzlich eingehen, soll jedoch ihr Verfasser dem Verständnis des Lesers nähergebracht werden, ohne daß dabei beabsichtigt ist, irgendwelche neuen Daten beizubringen. Doch scheint es uns gerechtfertigt, eine Gestalt im ärztlichen Kreise des deutschen Sprachgebietes einmal aufleben zu lassen, die in dieser Hinsicht sicher entschieden zu kurz gekommen ist.

Ich denke auch keineswegs daran, in Form eines Querschnitts Blacks Zeit vor Augen zu führen, obgleich die Jahrzehnte seines Wirkens ohne Zweifel zu den, auf die ganze Breite gesehen, größten Epochen der Geschichte Schottlands gehören. Überdies ist bemerkenswert, daß Männer wie Adam Smith, David Hume und James Watt, mit denen sich für den heutigen Gebildeten bestimmte Begriffe verbinden, sowie der Geologe James Hutton alle zum Freundeskreis unseres Arztes gehörten. Nehmen wir seinen Lehrer William Cullen (1712-1790) hinzu, so ist einigermaßen zum Ausdruck gebracht, in wie vielen Farben das Zeitalter der Aufklärung im Norden der Britischen Insel geleuchtet hat.

Mathieu Maty (1718-1776), einer der ersten Biographen Boerhaaves und sehr eifriger medizinischer Bibliothekar, nennt, wie Speter ausführt, drei Arten von Lebensbeschreibungen großer Männer: die erste aus einzelnen Daten und Leistungen aufgebaute, die zweite als Teil eines kritischen Querschnitts und Längsschnitts und die dritte nach den innerlichen Neigungen, die angebe, wie jene Gestalten gewesen sind. Diese bemühe sich, «das in Finsterniß begrabene Verdienst, und die Kleinheit unter der Larve der Größe» aufzudecken (zitiert nach Speter, in Das Buch der großen Chemiker I, S. 205 f.). Hier geht es uns vor allem darum, ein derartiges Charakterbild zu entwerfen, aus dem verständlich werden soll, weshalb Black zu seiner Zeit keine größere Wirkung in die Breite gehabt hat.

Aus allen seinen Aufzeichnungen wird indessen klar, daß es ihm gar nicht um Wirkung zu tun war. Die vielen einzelnen, so überaus sympathischen und originellen Züge lassen ihn als stillen, seine unmittelbare Umgebung nachhaltig beeinflussenden Gelehrten erscheinen, der treu seinen Pflichten oblag und des Wertes seiner wenigen, aber gediegenen Leistungen sicher war. Wilhelm Ostwald hat bekanntlich in seinem Werk Große Männer als zwei Extreme von Forschertypen den klassischen und den romantischen Typus voneinander abgegrenzt und die «mentale Reaktionsgeschwindig- 
keit», die beim ersten klein, beim zweiten groß sei, als maßgebend für die Beurteilung bezeichnet. Jener strebt in zurückgezogener, zäher, beharrlicher, spät einsetzender Arbeit, wobei er die einzelnen Mosaiksteinchen seiner Entdeckungen sorgfältig aneinanderfügt, nach «allseitiger Vollendung» jeder Leistung. Diesem geht es um raschen Erfolg, er sucht nach unmittelbarer starker Wirkung auf die Zeitgenossen, sammelt deshalb Schüler um sich, die er mit den verschiedensten Aufgaben betraut. Schon früh mit seiner Produktion einsetzend, läßt er seine Veröffentlichungen Schlag auf Schlag folgen.

Unsere ersten Andeutungen lassen bereits erkennen, auf welcher Seite, wenn man Ostwalds Schema anwenden will, Black zu suchen sein dürfte. Es ist verlockend, dessen Zügen im einzelnen nachzugehen und damit an einem weiteren Fall zu zeigen, daß das Gegensatzpaar des deutschen Chemikers nicht schlecht gewählt ist. Ohne Zweifel haben wir in Black den klassischen Typus vor uns. In Südfrankreich geboren und in seinen Knabenjahren nach der väterlichen Heimat verpflanzt, begibt sich der vom Unterricht Cullens gefesselte Medizinstudent nach Abschluß seiner Ausbildung als Assistent zu seinem Lehrer, bei dem er nun jahrelang sich einem bestimmten Problem hingibt, dessen grundlegende Bedeutung ihm im Verlauf seiner Analyse aufgegangen ist. Ungefähr fünf Jahre verbringt er über seinen Untersuchungen an Kalk und Magnesia, und die Bemerkung seines Biographen und jüngeren Freundes JoHs Roвison (1739-1805), daß er langsame Fortschritte gemacht habe, immer maßvoll und nüchtern gearbeitet und den Termin seiner Promotion wegen einer wissenschaftlichen Arbeit um drei Jahre hinausgeschoben habe, ist äußerst charakteristisch. Nach dem Erscheinen seiner Dissertatio de humore acido a cibis orto, et magnesia alba (1754) sollte es nochmals zwei Jahre dauern, bis die oben erwähnte umfassende Abhandlung veröffentlicht werden konnte. $\mathrm{Da} ß$ er Zeit seines Lebens über die ganzen Laboratoriumsarbeiten ein Tagebuch führte und außerdem in einem Notizbuch offenbar spezielle Protokolle niederschrieb, verrät das $\mathrm{Ma} ß$ an Umsicht, mit der er dabei zu Werke ging.

Diese klassischen Erstlingsarbeiten, die von einzelnen seiner Landsleute unmittelbar neben Newtons Optik eingereiht wurden, bilden den Abschluß der ersten Lebensperiode. Relativ spät für jene Zeit war er zu einer hervorragenden Leistung gelangt, aber die in ihrem logischen Aufbau und in ihrer Gediegenheit einzigartige Leistung war lange genug gereift, um nun unmittelbare Früchte zu tragen. Als Nachfolger Cullens lehrte Black nun Anatomie, später Medizin und Chemie in Glasgow. In seiner ruhigen Art muß er 


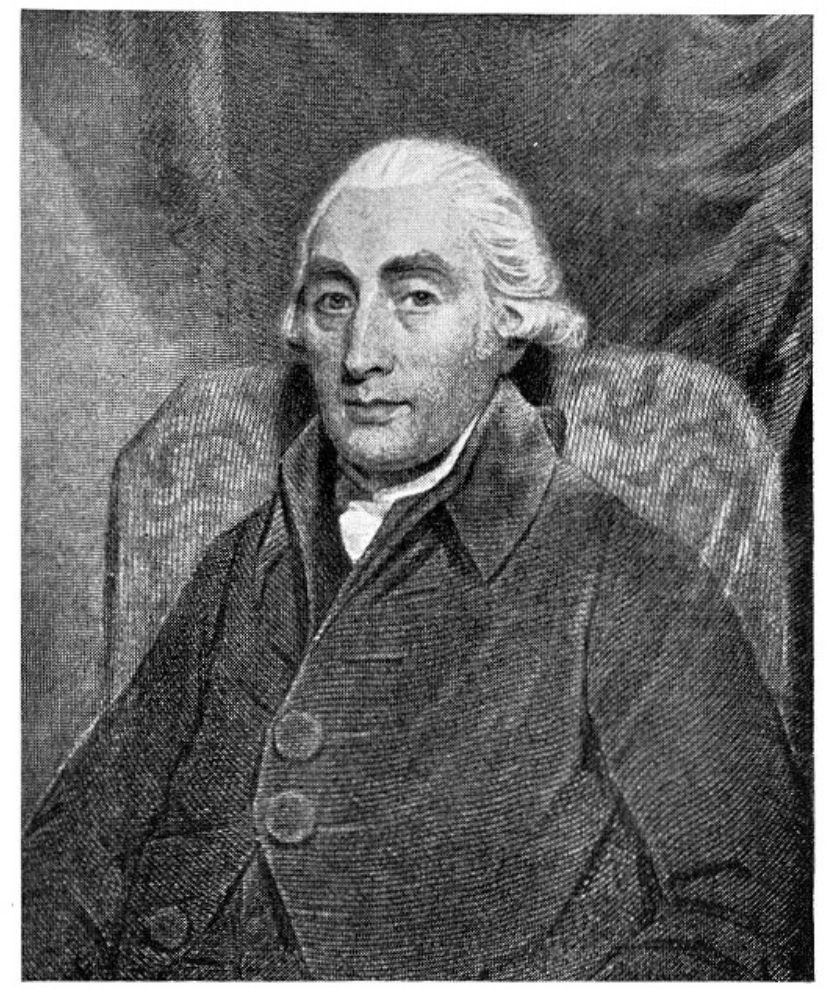

Abb. 1. Joseph Black (1728-1799), dessen Abhandlung des Jahres 1756 eine neue Ära der Chemie eröffnete. Stich von CoNRAD CooK (19. Jahrhundert) nach einem Gemälde von Sir Henry Raeburn 


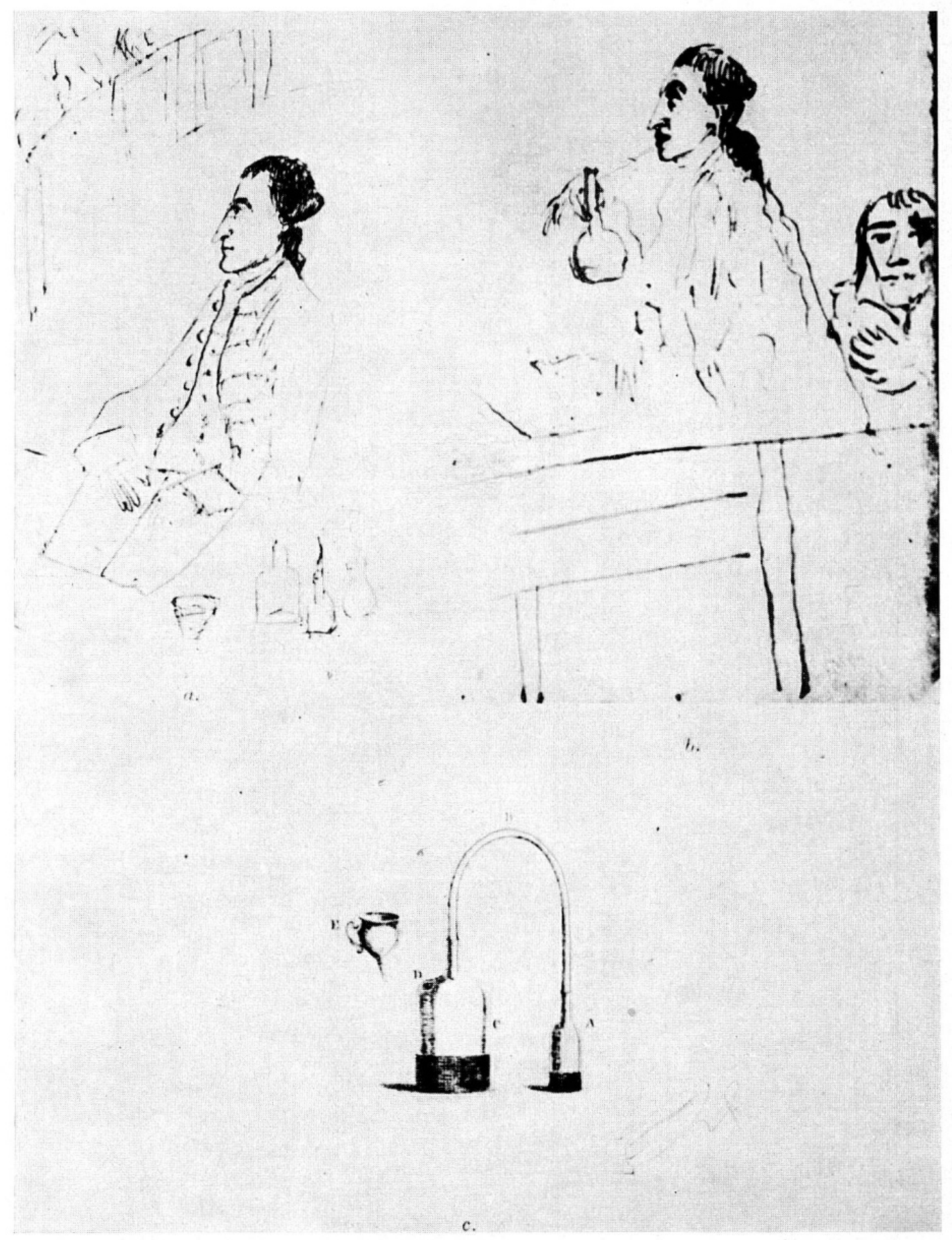

Abb. 2. Zeichnungen von Thomas Cochrane

aus der Vorlesung J. Blacks in den Jahren 1767/68 (aus: D. McKIE, Annals of Science, vol. 1, s. Bibliographie; Reproduktion dank der Freundlichkeit der Wellcome Historical Medical Library, London) 
auf seine Zuhörer und seine Patienten, namentlich auch die Frauen, eine starke Anziehung ausgeübt haben, ohne daß er jedoch eine seinen hohen Ansprüchen genügende Lebensgefährtin fand. Vom nächsten Dezennium an finden wir Black, wiederum als Nachfolger seines Lehrers, als Professor der Chemie in Edinburgh, wo er bis zu seinem Tode wirkte.

Das Bild aus seinen Jugendjahren gibt nur einen unvollständigen Eindruck von der Persönlichkeit des angesehenen und einflußreichen schottischen Arztes. Es sei daher durch einige weitere Züge ergänzt, soweit sie uns von seinen Zeitgenossen und Schülern vermittelt wurden. Jahr für Jahr trug er in solider, auf der Phlogistonlehre aufgebauter und von Cullen ausgehender Systematik die Elemente der Chemie vor. Dabei ging es ihm, wie Robison berichtet, in erster Linie darum, den Zuhörern - unter denen offenbar Laien und Damen stark vertreten waren - allgemeine Kenntnisse und Vorstellungen zu vermitteln. Es paßt zum Bilde von Blacks Persönlichkeit, daß er keine eigentliche Schule gegründet hat, wenn auch manche nachher berühmt gewordene Chemiker und Techniker (CAvendish, WATT, William Irvine) von ihm gefördert worden sind. Dabei müssen die reichlich vorgeführten Experimente als Funken gezündet und fähige Köpfe vor allem auch in physikalischer Richtung nachhaltig beeinflußt haben.

Hier ist denn auch Blacks zweite große Tat zu nennen, die ebenso lange vorbereitet war und daher als ebenso vollendetes Erzeugnis seinen Namen unsterblich gemacht hat. Ich meine die bereits im ersten Abschnitt erwähnte Entdeckung der latenten Wärme, die ihm nach langen, beharrlich verfolgten Versuchen mit dem Schmelzen von Eis gelang (1762 erstmals vorgetragen). Auch hier ist charakteristisch, wieviel Zeit verfließen sollte, bis diese Entdeckung allgemein bekannt wurde, nämlich erst durch die von seinem Nachfolger in Glasgow, Robison, herausgegebenen Vorlesungen, auf die wir später zurückkommen werden. Diese Entdeckung, um deren zeitliche Priorität er sich mit dem schwedischen Physiker Johann CarL WiLcke (1732-1796) streitet, bildet die Grundlage der modernen Wärmelehre.

Über sein späteres Leben sagt Black selber, daß er vielfach durch Amtspflichten von seiner Laboratoriumsforschung abgehalten worden sei. Für die kleine Zahl von wissenschaftlichen Arbeiten ist jedoch sicher auch Blacks Abneigung vor dem Schriftstellern verantwortlich zu machen. Seine stoische Ruhe, die ihn im großen ganzen auch vor Polemiken bewahrte, und die peinliche Ordnung, die seinen Alltag beherrschte, ließen ihn vor etwas Halbem zurückschrecken. Und in einer Zeit, in der sich alles in der Chemie 
in lebhaftem Fluß befand - dazu hatte nicht zuletzt seine eigene Untersuchung Anlaß gegeben -, zog er es vor, in aller Stille seine Vorlesungen zu halten und gewissermaßen aus der Proszeniumsloge den Gang der Entwicklung zu verfolgen. $\mathrm{Da} \beta$ er selber an den vielen neuen Entdeckungen, die zum Sturze der Phlogistonlehre führten, nicht unbedeutenden Anteil hatte, mag ihn mit Befriedigung erfüllt haben. So vermochte er auch dem jungen Draufgänger in Paris, der in der Hitze der Arbeit allzu leicht vergaß, wieviel er gerade dem Professor in Edinburg verdankte, neidlose Anerkennung zu zollen.

Die geringe Aktivität nach außen mag auch verständlich sein aus dem lebhaften Umgang mit älteren und jüngeren Freunden. Nicht umsonst hatte Montesquieu, der dem Elternhaus nahegestanden hatte, dem Vater zur wissenschaftlichen Leistung seines Sohnes gratuliert, was doch wohl Blacks weite allgemeine Interessen beweist. Es scheint, als hätte er einmal eine Lungenkrankheit durchgemacht; jedenfalls wird von mehrmaligen Hämoptoen berichtet. Dieses Kränkeln legte ihm große Zurückhaltung auf und führte dazu, daß er sich mehr und mehr mit seiner eigenen Gesundheit beschäftigten mußte. Wie ein Weiser, der sich von Schicksalsschlägen nicht niederbeugen ließ, verbrachte er die letzten Jahre seines Lebens.

\section{Heuristische und experimentelle Prinzipien in Blacks chemischer Analyse}

Einer seiner Biographen, der berühmte Henry Brougham (1778-1868), der Gründer der Universität London, schreibt über Blacks Experimentierkunst: «Der lange Tisch, auf dem die verschiedenen Vorgänge ausgeführt worden waren, war so sauber am Ende der Vorlesung, als er gewesen war, bevor der Apparat draufgestellt worden war ... Nicht ein Tropfen Flüssigkeit, nicht ein Körnchen Staub blieb zurück» (zitiert nach Ramsay).

Wir stellen dieses vielleicht etwas übertriebene Bild des gewandten Experimentators an den Anfang unseres Überblicks über Blacks Abhandlung, weil es uns einen Eindruck vermittelt auch von der geistigen Sauberheit und der logischen Struktur des Mannes, der als der Schöpfer der exakten pneumatischen Chemie in die Geschichte der Wissenschaften eingehen sollte. $\mathrm{Daß}$ ihm ein weiteres Ruhmesblatt gebührt, wird der folgende Abschnitt zeigen. 
Es sei nun versucht, diesen streng logischen Aufbau der klassisch gewordenen einzigen, auch selbständig erschienenen Abhandlung ${ }^{3}$ anhand der Quelle und der späteren Würdigungen ${ }^{4}$ kurz zu skizzieren. Dabei wird ausschließlich von der obgenannten ausführlichen Arbeit ausgegangen, von der die Dissertation nur ein Teilstück darstellt.

Den Ausgangspunkt bildete eine medizinische Streitfrage, die übrigens zeigt, wie eng damals die Chemie mit der Medizin verflochten war. Es handelt sich darum, zu entscheiden, ob einem zur Auflösung von Blasensteinen angepriesenen Mittel, das u. a. aus kalzinierten Schnecken bestand und von Mrs. Jeane Stephens für viel Geld verkauft worden war, irgendwelche Wirksamkeit zukam. Von Cullen und seinen Mitarbeitern wurde dies bestritten. Black selber war der Ansicht, daß man anstelle dieser Wunderformel, deren Veröffentlichung der raffinierten Frau 5000 Pfund Sterling eingetragen hatte, ebenso gut ein mildes Alkali wählen könne. Dafür schlug er das Epsomersalz vor, das zur Hauptsache Magnesiumsulfat enthält und weit weniger eingreifend ist als der Ätzkalk oder gar der Höllenstein, die zur Erhaltung der Kaustizität ebenfalls empfohlen worden waren.

Den chemischen Ausgangspunkt nahm die Untersuchung von der Magnesia und vom Ätzkalk. Dessen kaustische Eigenschaften führte man damals auf das Feuer zurück, in dessen Hitze der Kalk geglüht wurde. Eine geheimnisvolle Kraft sollte beim Glühen vom Feuer auf die Kalksteine übergehen. Das Mildwerden des Kalkes beim Kochen mit milden Alkalien (z. B. Natriumkarbonat) bestehe in einem Übertreten dieses Feuerstoffes an die Alkalien.

Im ersten Teil von Blacks Arbeit lassen sich nun sehr deutlich vier Schritte nachweisen, und jeder Schritt ist - ganz im Sinne der späteren

3 Blacks Vortrag aus dem Jahre 1755 erschien, zusammen mit W. Cullens An Essay on the Cold Produced by Evaporating Fluids, and of Some Other Means of Producing Cold separat in Edinburgh 1777 (printed for William Creech, Edinburgh; and for J. Murray, and Wallis and Storrehouse, London.) Eine bisher nirgends erwähnte deutsche Bearbeitung eines Teiles dieser Abhandlung findet sich in Auserlesene kleine Werke dreyer berühmter Englischer Chymisten, Herrn Priestley, Henry und Black, Die Schwängerung des gemeinen Wassers mit fixer Luft, die Magnesia und Kalkerde, die fäulungswidrige Kraft gewisser Arztneyen und andere erhebliche Gegenstände betreffend. Kopenhagen und Leipzig, bei Johann Friedrich Heineck und Faber, 1774. Diese Ausgabe erfolgte «auf den Rat geschickter Ärzte» (Greding?, Erxleben?), ohne daß auch nur der Übersetzer genannt würde. Vgl. dazu M. SPeter, a. a. O. (Literaturverzeichnis). Auf Thomas Henry werden wir später zurückkommen.

4 Besonders Sir William Ramsay (1852-1916) und Max Speter, s. Literaturverzeichnis. 
Philosophie der Experimentalmedizin von Claude Bernard - durch einen klaren logischen Gedankengang mit dem vorherigen verknüpft. Der erste Schritt bestand darin, daß Black die feurige Materie, die beim Mildwerden (auch schon nur beim Stehen an der Luft) des Kalkes entwich, einzufangen suchte. Zu seiner großen Verwunderung entwich jedoch nichts. Vielmehr heißt es in seinem Notizbuch: «Nichts entweicht - das Gewicht nimmt erheblich zu durch Luftabsorption.»

Im zweiten Schritt ging es Black darum, eine Vergleichsbasis zu gewinnen. Er wählte dazu ein Stück Kreide, das eine Unze (etwa 30 g) schwer war, als mildes Alkali, und verglich dessen Gewichtsverlust beim Kalzinieren (Glühen) mit demjenigen, den es bei Zusetzen von «Salzgeist» $(\mathrm{HCl})$, d.h. bei der altbekannten Efferveszenz, erlitt. Er begann nun die Ursache der «Mildheit» bzw. Kaustizität zu ahnen, und ein Eintrag wiederum einige Seiten später zeigt (alles nach Ramsay), daß er den Übergang von Luft vom Alkali an den Kalk als die Ursache von dessen Mildwerden erkannt hatte. Damit war der Begriff erstmals schriftlich formuliert, der sich hier erstmals scharf fassen ließ, nämlich das Übertreten von «Luft» von einem Stoff an den andern. Ein großes neues Feld der Forschung hatte sich damit aufgetan.

Diese Gedankenkette ergibt sich aus dem handgeschriebenen Notizbuch. In der gedruckten Abhandlung wird das Parallelbeispiel des Epsomersalzes, also des Magnesia enthaltenden Stoffes gewählt. Der Unterschied im Verhalten des Epsomersalzes $\left(\mathrm{Mg} \mathrm{SO}_{4}\right)$ und des Kaliumkarbonats gegenüber den verschiedenen Säuren, und das Kochen der Salze von Magnesium mit «Salzammoniak» in der Retorte, wobei flüchtige Kristalle von Riechsalz entstehen, zeigten Black folgendes: «Während die Säure aus dem Kalksalz an die Magnesia übergeht, wird bei Zusatz eines gelösten Alkalis wiederum ,milde ${ }^{6}$ Magnesia ausgefällt. Nicht nur ,Luft ${ }^{\star}$ ließ sich also austauschen, sondern auch der Teil eines Salzes.»

Nun wandte Black, wie aus der gedruckten Abhandlung hervorgeht, seine Aufmerksamkeit dem flüchtigen Teil zu, dessen Verlust beim Erhitzen 7/12 des Gewichtes ausmachte (damit war die erste Andeutung einer quantitativen Fragestellung gegeben). Diesen Verlust stellte er in der früher angegebenen Weise wieder her. Durch diese Behandlung mit mildem Alkali hatte die Magnesia ebensoviel an Gewicht zugenommen, als sie im Feuer verloren hatte; und da sie mit Säuren efferveszierte, mußte ein Teil der Zunahme auf Luft beruhen (=dritter Schritt). Ramsay schreibt dazu (S. 444): «Black hatte hier einen gewaltigen Schritt getan; er hatte ein 
kombiniertes Gas gewogen.» Aus dieser Operation ergab sich die bekannte Austauschformel, wohl die erste, in der «Luft» als Teilkomponente figuriert:

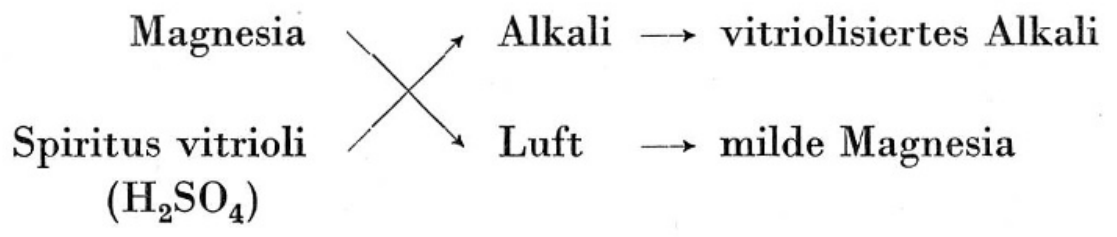

Der vierte Schritt stellte die ungefähre Gewichtsgleichheit des Verlustes durch Behandlung der milden Magnesia mit Säuren und durch Glühen fest. Damit war der erste Teil der Abhandlung beendigt.

Im zweiten Teil ${ }^{5}$ gelangte nun der beharrliche Forscher wieder zum Kalk zurück, von dem er offenbar laut seinen Notizen ausgegangen war. Es ließ sich kein Unterschied zwischen ursprünglichem und regeneriertem Kalk feststellen. Die Luft, die sich kombinieren ließ, mußte also den Charakter einer Säure haben, da sie sich mit einer scharfen Erde verband. Diese Erkenntnis entspricht offenbar dem «humor acidus» seiner Dissertation.

Nun handelte es sich darum, im dritten Teil der Untersuchung festzustellen, daß die nachgewiesene Luft nicht die gleichen Eigenschaften habe wie die atmosphärische Luft. Jetzt griff Black zur Luftpumpe von Boyle und Hales, mit der er aus einem Behälter mit Kalkwasser bzw. gewöhnlichem Wasser die Luft absaugte. Aus dem Experiment (= erster Schritt), das gleiche Luftmengen in beiden Fällen ergab, schloß Black, daß der Ätzkalk Luft von gewöhnlicher Beschaffenheit nicht anzog, aber imstande war, «sich bloß mit einer besonderen Art zu vereinigen, die in der Atmosphäre verteilt ist, entweder in Form eines sehr feinen Pulvers, oder, was wahrscheinlicher ist, einer elastischen Flüssigkeit.» Dieser gab Black einen bereits bekannten Namen, nämlich den der «fixen Luft», um keinen neuen Terminus in die Chemie einzuführen.

Auf diesen ersten folgte nun der ebenso entscheidende zweite Schritt, in dem Black darauf hinzielte, zur qualitativen auch noch die quantitative Erkenntnis (in Anlehnung an Hales) zu gewinnen, d.h. die Gewichtszunahme beim «Mildwerden» des Alkali zu bestimmen. Wie Ramsay feststellt, betrug bei diesen quantitativen Analysen der Fehler nur vier Prozent, ein in Anbetracht der einfachen Hilfsmittel außerordentlich gutes Resultat. Black war

5 Die hier vorgenommene Unterteilung entspricht unserer Interpretation. Die gedruckte Abhandlung ist nur in zwei Teile gegliedert. 
auch nicht weit entfernt von der Entdeckung, die dann Lavoisier machen sollte, daß «fixe Luft» von der Kohle gebildet wird.

Alle weiteren Einzelheiten der von sinnreichen, ja gerade in ihrer Einfachheit genialen Experimenten übervollen Untersuchung galten der Abklärung zeitbedingter Fragen, die in unserem Zusammenhang von geringerer Bedeutung sind. Auch die Anregungen für die Wärmelehre, die sich indirekt daraus ergaben, gehören nicht hierher.

Viel wesentlicher ist, was Black beim späteren Rückblick auf seine Versuche (Vorlesungen, Bd. II, S. 379) schreibt. Aus seiner langen Erzählung, die er darüber seinen Zuhörern darbietet, ergab sich ihm folgender Schluß: «Hier schien sich mir ein neues und vielleicht grenzenloses Feld zu eröffnen. Wir wissen nicht, wie viele besondere Luftarten in unserer Atmosphäre enthalten sein mögen und was für Eigenschaften diese besitzen.» Diese Äußerung zeigt zur Genüge, daß sich der ideenreiche Chemiker vollkommen bewußt war, welche Bedeutung seinen Analysen zukam. Ja, er scheint mit einer gewissen Wehmut auf die in der Zwischenzeit gemachten neuen Entdeckungen zurückzublicken, indem er (l. c., S. 393) die «fixe Luft» eine «zusammengesetzte Substanz» nennt, die als «Ausfluß der brennbaren Körper»durch «Phlogistikation» entstehe ${ }^{6}$. Sicher müssen wir der Verheißung des Chemikers recht geben, daß durch seine Untersuchung «ein helles Licht auf diesen Gegenstand und auf manche andere wichtige Teile der Chemie geworfen wurde» (l. c., S. 339). Es erfüllt ihn mit Befriedigung, daß die Chemiker nunmehr mit seinem neuen System übereinstimmen.

Die Entdeckung Blacks löste einen gewaltigen Sturm unter den Chemikern aus, der endgültig erst von Lavoisier gelegt werden sollte. Statt diese längst beschriebene Entwicklung zu verfolgen, ist es jetzt unsere Aufgabe, der viel zu wenig bekannten physiologischen Nutzanwendung nachzugehen, die Black aus seiner Untersuchung gezogen hat, und dann deren Ausweitung unter den jüngeren britischen Forschern kennenzulernen.

\section{Die biologische Wendung in Blacks Chemie}

Halten wir aus den vorhergehenden Abschnitten fest: Die Entdeckung des «Gas sylvestre» van Helmonts, das auch bei organischen Prozessen, wie Gärung und Fäulnis, entsteht, war durch Black in Form der sogenannten

6 Daraus ist auch ersichtlich, wie merkwürdig lange Black der Phlogistonlehre treu blieb. 
«fixen Luft» sowohl qualitativ wie bereits auch quantitativ in chemischen Reaktionen aus dem anorganischen Reich bestätigt und vertieft worden. Mit keinem Wort geht indessen der Schotte in seiner hervorragenden Abhandlung (1756) auf die Rolle der "fixen Luft» in der belebten Welt ein, abgesehen davon, daß er von Knochenasche usw. im Sinne von kalkartigen Substanzen schreibt.

Hier füllen nun seine später durch Robison im Drucke herausgegebenen und von seinem Schüler Lorenz von Crell (1744-1816) ins Deutsche übersetzten Vorlesungen eine gewisse Lücke aus ${ }^{7}$. Es ist nicht verwunderlich, daß Black zur Entdeckung der spezifischen Wärme gekommen ist, nehmen doch die physikalischen Darlegungen in seinen 1799 in englischer Sprache herausgekommenen Darlegungen einen breiten Raum ein. Dies trifft namentlich für den ersten Band zu, der den allgemeinen Teil enthält, darunter z.B. die Phlogistonlehre. Die Weite des Horizontes ihres Verfassers verraten auch die geologischen und geophysikalischen Abschnitte im Kapitel über die Erden, in denen z.B. die bahnbrechende Leistung von H.B. DE SAussure zur Sprache kommt.

Bei den alkalischen Erden wird nun der «fixen Luft» und ihrer Entdeckung viel Raum gewidmet (Band II, S. 339-410), und hier geht der Verfasser im Zusammenhang mit den verschiedenen Luftarten, die er nachgewiesen hat, auf seine im Anschluß an die berühmte Abhandlung vorgenommenen Experimente ein. Trotz seiner Ablenkung durch die Amtspflichten in Glasgow habe er 1757 zum erstenmal Nachricht von Versuchen gegeben, in denen er entdeckte, daß «die besondere Luftart, welche von den alkalischen Substanzen angezogen wird, allen Tieren tödlich ist, welche sie durch den Mund und die Nasenlöcher einatmen ».

Obgleich seit van Helmont, Boyle und schon früher derartige tödliche Gase gefunden worden waren - ich denke hier namentlich an die Vorkommnisse in Bergwerken (Paracelsus, Agricola) -, so liegt hier bei Black nun doch eine ganz andere Situation vor, indem man recht genau wußte, um

7 Der «Bibliothèque publique» in Genf sei für die langfristige Überlassung dieses Werkes gedankt. Es trägt den Titel D. Joseph Blacks, Professors der Chemie auf der Universität zu Edinburg, königlichen Leibarztes in Schottland, Mitglied der königl. Gesellschaft in Edinburg, der Akademie der Wissenschaften zu Paris, und der kayserlichen Akademie der Wissenschaften zu St.Petersburg, Vorlesungen über die Grundlehren der Chemie, aus seiner Handschrift herausgegeben von D. Johann Robison, Prof. d. Naturkunde in Edinburg. Die biographische Vorrede von RoBIson umfaßt 96 Seiten. Die drei Bände sind bei B.G. Hoffmann in Hamburg 1804 erschienen. 
was für einen gasförmigen Stoff es sich handeln mußte. Wir können deshalb die nachstehend von Black aus einer Distanz von ungefähr fünfzehn bis zwanzig Jahren referierten Versuche an Tieren und Menschen recht eigentlich als die physiologische Wendung in der Chemie oder als den Beginn chemischer Experimentalforschung in der Biologie bezeichnen.

So einfach diese Tierversuche in methodischer Hinsicht sind, so bedeutungsvoll sollten sie für das Denken der Ärzte und Chirurgen werden.

Im ersten Versuch verschloß Black einigen Spatzen die Nasenlöcher mit Fett und stellte fest, daß sie bei Einatmung des künstlichen Gases, d. h. der «fixen Luft», bei verstopften Nasenlöchern drei bis vier Minuten, bei offen zugänglichen Luftwegen dagegen nur zehn bis vierzehn Sekunden am Leben bleiben.

Es folgt nun die Anwendung dieser Erkenntnis auf den Menschen: «Auch überzeugte ich mich, daß die Veränderung, welche wir in gesunder Luft durch das Atmen hervorbringen, hauptsächlich, wo nicht allein, darin besteht, daß ein Teil derselben in fixe Luft umgewandelt wird. Denn ich fand, wenn man durch eine Röhre in Kalkwasser oder eine Auflösung von kaustischem Alkali bläst, daß alsdann Kalk niedergeschlagen und das Alkali milde wird.» Hier weist Black auf die oben erwähnten ähnlichen, aber bloß gewichtsmäßig beurteilten Versuche Hales' mit den feuchten Diaphragmen hin.

Dieses Protokoll seines großen Vorgängers weist ihm nun den Weg zu dem wohl ersten Massenexperiment an Menschen, das in der modernen Biologie bekannt geworden ist. Leider wird es nur vom Herausgeber offenbar aus seiner eigenen Erinnerung erzählt. Aber wahrscheinlich hat ihm Robison damals bei diesen Versuchen assistiert: «Im Winter 1764/65 machte Dr. Black eine beträchtliche Menge kaustisches Mineralkali milder, indem er es in einem Apparate, welcher über eines der Luftlöcher in der Decke einer Kirche [von Glasgow] gesetzt wurde, in welcher eine Versammlung von mehr als 1500 [Menschen] beinahe zehn Stunden lang gewesen war, langsam durch Lumpen filtrieren ließ.» Diese lakonische Anmerkung Robisons (zu Seite 381) bedarf keines weitern Kommentars. In seiner Art steht dieser Versuch wohl im 18. Jahrhundert einzig da, er macht auch deutlich, welcher origineller Methoden sich der beliebte Arzt damals bediente.

Und noch einmal weitet Black seine Untersuchung aus, indem nun die alten Äußerungen von HeLmonts aufgenommen und auf exakter Basis analysiert werden. Die «fixe Luft » ist nämlich auch « der Hauptteil der elastischen Substanz », « welche sich in den Flüssigkeiten bei der weinigen Gärung bildet». Zur Nachprüfung dieser «aufs Geratwohl» geäußerten Hinweise des belgischen Arztes zeigt er, daß Kalkwasser «über Garwürze» getrübt wird.

Diese in der Inauguraldissertation bekanntgemachten Versuche habe er andern mitgeteilt. Und diese hätten sich dann der Materie zugewendet. 
Hier werden dann auch die Arbeiten über die Säuerlinge von Spa (Brownrigg 1741) sowie die Fortschritte der pneumatischen Chemie referiert (Cavendish, Priestley, Lavoisier u.a.). Auch die Anwendung des Gases in der Behandlung der Lungenauszehrung kommt zur Sprache. Black hat also die gesamte von ihm inaugurierte Entwicklung aufmerksam verfolgt. Von einer steinauflösenden Wirkung derartiger Wasser will der um seine Kranken besorgte schottische Arzt jedoch nichts wissen. Er spricht ihnen höchstens palliativen Einfluß zu.

Damit haben wir das wohl für die Medizingeschichte wichtigste Kapitel des großen Werkes von Black kennengelernt. Von welcher Bedeutung es für die unmittelbare Folgezeit wurde, soll jetzt an einigen Beispielen skizziert werden.

\section{Die Ausweitung der chemischen Forschung in der Biologie [Macbride, Henry]}

Die zweite Hälfte des 18. Jahrhunderts ist insbesondere in Großbritannien eine Zeit der emsigsten Forschung auf allen Gebieten der durch Hales und Black zu neuem Leben erweckten Chemie. Die exakten Versuche des letzteren wirkten wie ein Katalysator, was vor allem für seinen kühnen Streifzug in die Gefilde der biologischen Wissenschaften gilt. Wenn auch die Ergebnisse erst am Ende des Jahrhunderts gedruckt erschienen, so muß man doch ohne Zweifel annehmen (vgl. Blacks oben erwähnte Äußerung), daß die mündliche Übermittlung von der damals in voller Blüte stehenden Edinburger Schule aus hohe Wellen warf.

Allerdings sollte ihr bald London als neues Zentrum experimenteller Forschung den Rang streitig machen. Es kommt hinzu, daß dort in der Person des einflußreichen ehemaligen Generalarztes Sir John Pringle (1707-1782) gerade der medizinischen Biologie ein höchst tatkräftiger Förderer erwuchs, was z.B. darin zum Ausdruck kommt, daß tüchtige Forscher (wie etwa Jan Ingenhousz) nach England gezogen wurden. Von Pringle erschienen im Jahre 1752 die Observations on the Diseases of the Army (deutsche Übersetzung von Joh. Ernst Greding, Altenburg 1754), die, zusammen mit Hales' Werk und Blacks Abhandlung, nun eine neue Forschungsrichtung in die Wege leiten sollten.

Im Anhang, der zur Bekämpfung der Seuchen in der Armee neue «Versuche und Beobachtungen über septische und antiseptische Substanzen» brachte, teilte der Begründer der Militärhygiene mit, daß die «minerali- 
schen Acida» kräftige Antiseptika seien und untersuchte dann auch das Kalkwasser daraufhin. Wichtiger als diese Experimente ist das, was Pringle der «Royal Society» im Frühjahr 1761 «über die Fäulnis des Blutes und anderer tierischer Substanzen» berichtet. Er nimmt nämlich, wohl im Anschluß an seinen Lehrer Boerhaave, «in der Composition aller tierischen Körper ein verborgenes Acidum» an, das «eines von den Hauptingredienzien in dem Kitte zwischen den Teilchen » sei, «die eine Faser ausmachen ». Die Alkalien wirken durch ihre Absorptionskraft auflösend auch auf das Gewebe. Im 48. Versuch weist Pringle auch «Luft» im menschlichen Blutserum nach und bringt den Skorbut in Zusammenhang damit, ohne sich indessen weiter über diese Frage zu äußern.

Dieses vielgelesene Buch des militärärztlichen Praktikers war bereits bekannt, als nunmehr von der wissenschaftlichen Seite seinen theoretischen Vorstellungen wesentlich Vorschub geleistet wurde. Wie naheliegend mußte es nach Blacks Nachweis der «fixen Luft» bei der Atmung und Gärung sowie nach dem Hinweis auf ihren Säurecharakter sein, die älteren Vorstellungen Pringles damit in Zusammenhang zu bringen? Es waren nun Männer, die praktische Erfahrung mit wissenschaftlichem Eifer und oft auch wirtschaftlichen Ambitionen zur Bearbeitung dieser in der Luft liegenden Fragen verbanden. Unter der sicher großen Zahl von Forschern nennen wir je einen Schotten und einen Engländer als Vertreter des immer aktiver werdenden Standes der Chirurgen und Apotheker.

In der Reihe der ersteren ragt David Macbride (1726-1778), Chirurg und später «Medicinae Doctor» in Dublin hervor, dessen fast dreihundert Seiten umfassende Experimental Essays on Medical and Philosophical Subjects innert kurzer Zeit in zwei Auflagen erschienen (London 1764, 1767; von uns wurde die zweite, etwas erweiterte Auflage benützt). Der Autor schließt bewußt an Hales, Pringle und vor allem an Black an. Als einstigem Schiffschirurgen ist ihm auch die Verhütung des Skorbuts ein Herzensanliegen. Diese Ausgangspunkte veranlassen ihn zu Dutzenden von geschickt angeordneten pneumatischen Versuchen, für die er über Black hinaus äußerst sinnreiche Apparate entwickelt und auch abbildet. Hier sollen nur die biologisch-physiologischen Anwendungen dieser Arbeit zur Sprache kommen, da sie später oft lobend erwähnt wurden und ihnen daher für die Neuorientierung von Physiologie und Chemie sicher wesentliche Bedeutung zugeschrieben werden muß.

Auch für Macbride steht das «Zementprinzip» der belebten Materie, dem Albrecht Haller ganz am Anfang seiner Elementa physiologiae (1756) 
als «aer vinculum elementorum primarium» zu neuem Daseinsrecht verholfen hatte, im Vordergrund. Nun ist diese «unmittelbare Ursache» der «Kohäsion der Teile» für den schottischen Chirurgen in plausibler Argumentation nichts anderes als die «fixe Luft» Blacks. Den Säurecharakter dieses Zements hatte ja bereits Pringle vermutet. Dieses chemische Prinzip zur Erklärung der Fäulnis, die also in einem Verlust der «fixen Luft» beruhte, lag viel näher als die nach seiner Ansicht abwegigen Vorstellungen der Iatrophysiker, welche die "putrefactive acrimony» auf einen Verlust der scharfen eckigen Partikelchen aus den Blutkörperchen oder aus den Flüssigkeiten zurückführten?

Da auch die Gärung im lebenden Organismus auf dem Freiwerden dieses Prinzips (der «fixen Luft», des «subtilen Gases» von Macbride) beruht eine Erkenntnis, zu der der Verfasser vielleicht unabhängig von Black gelangt ist -, liegt es nun nahe, auch die Verdauung in den «ersten Wegen» (die ja bei den Iatrochemikern als «fermentatio» galt) auf ein Freiwerden der Kohlensäure zurückzuführen. Sie gelangt als «fixed Air» mit der Nahrung in den Körper und dann über den Chylus ins Blut. Dies ist das Wesen des Verdauungsprozesses nach Macbride, wie er im ersten Teil seines Werkes ausführt, ohne allerdings einen umfassenden experimentellen Beweis für seine Anschauung zu erbringen. Fäulnis, Gärung und auch die Verdauung sind also, zusammenfassend gesagt, nichts anderes als Prozesse, bei denen die «fixe Luft» eine wichtige Rolle spielt.

Diese Lücke des ersten Teiles füllt nun der zweite, Essay on the Nature and Properties of Fixed Air, teilweise aus. Hier schildert der Verfasser zahlreiche Versuche mit tierischen Substanzen, deren Fäulnis nach seinen Ergebnissen auf dem Verlust jenes «Prinzips» beruht. Es gelingt ihm, mittels «caustic volatile alcali» bei diesen putriden Prozessen die «fixe Luft» nachzuweisen. So läßt er im 16. Experiment (S. 70 ff.) Hammel- und Ochsenfleisch in gewöhnlicher und komprimierter Luft sowie im Vakuum faulen, wobei ihm in allen Fällen mit Blacks Methode die Bestimmung der entstandenen Kohlensäure gelingt. (Dabei spielt natürlich die Frage der Urzeugung der Fäulniserreger mit hinein, die seit den Versuchen von J. T. Needham (1745) neues Interesse gewonnen hatten. Doch kann hier nicht auf diese Frage eingegangen werden.)

Nachdem bei der Gärung von pflanzlichen Stoffen (z.B. Zucker) der $\mathrm{CO}_{2}$-Nachweis geglückt war, ist von besonderer Bedeutung, daß auch beim Zusetzen von Galle und Speichel zu organischen Substanzen dieses Gas entstanden war. Der 15. Versuch (S. 59 ff.) an Spatzen stellt eine Wieder- 
holung ähnlicher früherer Untersuchungen von Boyle, Mayow, Hales und Black mit besserer Methode dar und gipfelt im chemisch-analytischen Beweis, daß durch die Atmung «elastische» in «nicht elastische» Luft, also $\mathrm{CO}_{2}$, verwandelt wird.

Den Höhepunkt sämtlicher Experimente Macbrides bedeutet die schon von Lavoisier (l.c., S. $474 \mathrm{ff}$.) speziell hervorgehobene Bestimmung der «fixen Luft» in «verschiedenen Körperflüssigkeiten», nämlich Schweiß, Speichel, Galle, Brustmilch und Blut. Merkwürdigerweise sind diese Versuche (Experimente 17 bis 25) im letzten Teil des Werkes geschildert (Titel: On the Dissolvent Power of Quicklime, etc.), wo man sie gar nicht sucht, wie denn überhaupt das Erstlingswerk des Schotten in der Anordnung seiner Protokolle eine gewisse Unbeholfenheit erkennen läßt. Wir greifen hier lediglich den Abschnitt über das Blut heraus, dessen wörtliche Übersetzung gerechtfertigt sein dürfte:

«Experiment 22 (S.269).

Nachdem ich einige Unzen menschlichen Blutes bestellt hatte, das einer gesunden Person entzogen worden war, und die Trennung in Serum und ,Crassamentum ' abgewartet hatte, mischte ich zwei Drachmen (= etwa 7,2 g) Serum mit einer Unze (etwa $30 \mathrm{~g}$ ) Kalkwasser: Keine Veränderung trat ein; die Mischung blieb durchsichtig, und nach achtundvierzig Stunden konnte kein Niederschlag gefunden werden.» Im Serum war also keine «fixe Luft» enthalten.

«Experiment 23.

Ungefähr zwei Drachmen ,Crassamentum ' desselben Blutes wurde in ein Glas mit einer Unze Kalkwasser gebracht und fünf Tage stehen gelassen, wobei es sich weder auflöste noch putrid wurde. Nachdem ein Teil davon herausgenommen und mit Spiritus vitrioli (= Schwefelsäure) übergossen worden war, trat eine Efferveszenz ein. Der Kalk, der das Crassamentum durchsetzt und sich mit der fixen Luft verbunden hatte, zerplatzte nun in jedem Teil davon, im Augenblick als die Säure dazugefügt wurde.

So scheint die fixe Luft eng verbunden mit den roten Blutkörperchen, und zwar mit dem Teil des Blutes, den Senac die lympha coagulabilis genannt hatte; denn beide bilden das crassamentum.»

«Experiment 24 (S.270).

Zwei Unzen Kalkwasser wurden in ein großes Trinkglas geleert, ungefähr eine halbe Unze Blut wurde aus der Vene einer gesunden Person in das Glas mit Wasser gelassen. Als es sechs Stunden gestanden hatte, wurde die Mischung abgeschüttet bis auf eine Drachme, die auf dem Boden des Glases übrig blieb. Auf dieses Sediment wurde etwas Spiritus vitrioli getropft, was ein schwaches Aufbrausen bewirkte. Die kalkige Substanz wurde weiß, als sie beim Zusatz von Säure aufbrauste. So kann also fixe Luft leicht aus frischem Blut entwikkelt werden.»

Damit war der im ersten Teil ausgesprochene Sachverhalt wenigstens teilweise experimentell gestützt, eine der frühesten chemischen Teilanalysen 
eines Körpersaftes des Menschen, die zudem ausgerechnet einen gasförmigen Stoff aufgedeckt hatte. Es ist sehr gut verständlich, daß die Schrift Macbrides außerordentliches Aufsehen erregte und dem bis dahin unbekannten Chirurgen zu großem Ansehen im Reich der Wissenschaften verhalf. Wir gehen wohl nicht fehl, wenn wir auch die Anfänge der wissenschaftlichen Hämatologie, wie sie um jene Zeit William Hewson (1739-1774) in die Wege leitete, mit diesen Vorarbeiten in Verbindung bringen.

Bevor wir die chemische Linie noch ein Stück weiter verfolgen, sei noch hingewiesen auf die beiden weiteren Kapitel in der hervorragenden Schrift Macbrides, die über Antiseptika und über Skorbut handeln. Die Versuche über fäulniswidrige Stoffe, auf die wir nicht weiter eingehen, liegen in der Linie der Anregungen von Pringle, übertreffen jedoch jene weit an Fragestellung und Zweckmäßigkeit der Anordnung. Sie gipfeln in der Vorstellung von der alkalischen Natur der faulenden Stoffe, was wieder auf die «fixen Luft» als Prinzip der Kohäsion hinausläuft. Weniger glücklich sind die doch allzu spekulativen Vorschläge Macbrides, den Skorbut als putride Krankheit durch Zufuhr des «Zementprinzips», d.h. stark gärender Stoffe, wie Malz, Melasse usw., zu verhüten bzw. zu behandeln. Gegenüber der empirisch gewonnenen Empfehlung des Zitronensaftes als Prophylaktikum, die in Anlehnung an JoHN Woodall (der von Macbride ausführlich zitiert wird) vom Begründer der Schiffshygiene, James Lind (1716-1794), schon ein Dezennium früher erfolgt war, kamen die gutgemeinten Vorschläge des Dubliner Chirurgen nicht auf.

Der zweite Gelehrte, der die Anregungen Pringles und Blacks aufnahm, ist Thomas Henry (1734-1816), Apotheker und später Präsident der Philosophisch-Literarischen Gesellschaft von Manchester, der 1773 eine Schrift über Experiments and Observations herausgab, die auch ins Deutsche übersetzt wurde (s. oben Anmerkung 3). Diese Arbeit ist ohne größere Bedeutung für die Geschichte der physiologischen Chemie, sie muß aber auch auf dem Kontinent wegen ihres praktischen Nutzens sehr verbreitet gewesen sein und verdient deshalb hier wenigstens erwähnt zu werden. Es geht dem bis dahin wenig bekannten Verfasser, der auf Empfehlung Pringles und Priestleys in die «Royal Society» Aufnahme fand, später einige Schriften Lavoisiers ins Englische übertrug und auch Memories of Albert de Haller (1783) verfaßte, um zwei Fragen, nämlich die Magnesia alba für den medizinischen Gebrauch zu präparieren und durch bestimmte "Absorbentia» «die Fäulung» zu verzögern. Auch vegetabilischen Infusionen, die Kalk enthalten, kommt nach dem Autor antiseptische Kraft zu, «ohne die 
Kohäsion der animalischen Fiebren zu vermindern.»Wenn auch Henry nicht in allem mit seinen Vorläufern übereinstimmt, so ist doch ersichtlich, daß seine sehr gewinnbringenden Empfehlungen durchaus dem Problemkreis der Arbeit Blacks angehören und deshalb hier genannt zu werden verdienten.

Von Interesse mag noch sein, daß Henrys Biograph C.W. Sutron (Dict. Nat. Biogr.) darauf hinweist, daß der vielseitig interessierte Mann als erster den Nutzen der Kohlensäure für die Pflanzen erkannte, was wohl nicht stimmt (vgl. TröndLE), aber sicher aus dem Zusammenhang der damaligen pflanzenphysiologischen Untersuchungen zu verstehen sein dürfte. Damit ist wenigstens ein weiteres Betätigungsfeld angedeutet, das sich aus Blacks Dissertation ergab und der Biologie gewaltige Perspektiven eröffnen sollte.

Fragen wir uns zum Schluß dieses Abschnittes nach dem Urteil Blacks über seinen «Rivalen» Macbride, so ist für seine vorsichtige Haltung kennzeichnend, daß er von der «fixen Luft» als Kohäsionsprinzip der lebenden Materie nichts wissen will, da diese Anschauung nicht genügend begründet sei (Vorlesungen, Bd. 2, S. 383). Auf die wirklich positiven Versuche des Dubliner Kollegen geht er indessen mit keinem Wort ein, obgleich man hier von ihm eine Stellungnahme hätte erwarten dürfen. Um so besser kommt der weit aktivere Macbride gegenüber Black in der Beurteilung Lavoisiers weg. Und es mag sein, daß die ablehnende Haltung Blacks gegenüber Macbride, die sicher schon vor der Veröffentlichung seiner Vorlesungen publik wurde, die schwer verständliche Bevorzugung des letzteren durch den französischen Chemiker erklärt.

\section{Die Anfünge der pneumatischen Chemie und Medizin}

Wir würden die vorstehenden Ausführungen als unvollständig betrachten, wenn nicht zum Schluß noch ein Blick auf die chemischen und medizinischen Auswirkungen von Blacks großer Tat getan würde. Da es sich hier indessen um bereits Bekanntes handelt, sei versucht, diese Rückschau aus dem Gesichtswinkel von Black und vom Verhältnis Black-Lavoisier aus zu vermitteln.

Es wurde bereits gezeigt, daß der Edinburgher Chemiker, von dem Adam Smith gesagt hat, er kenne keinen Menschen «mit weniger Unverstand im Kopf» (zitiert nach Robison, Vorlesungen. I, S. XXXVIII), später sich auf die mündliche Verbreitung seiner Lehre beschränkte und der Phlogistontheorie merkwürdig lange treu blieb. Was nun Blacks Stellung 
im geschichtlichen Ablauf der Chemie bis zu seinem Tode betrifft, so darf man ihn mit Robison zu Recht als den «Zuschauer der glücklichen Fortschritte anderer» bezeichnen, wobei dieser Retter der Ehre Blacks wohl hauptsächlich auch an die von dessen Freund Watt erfundene Dampfmaschine denkt. In seinen Vorlesungen hat sich der Edinburgher Professor an verschiedenen Stellen eingehend mit der späteren Entwicklung der pneumatischen Chemie befaßt. Greifen wir die markantesten Stellen aus dem Kapitel über die «fixe Luft» heraus. Diese Bezeichnung im Blackschen Sinne blieb ungefähr zwei Jahrzehnte erhalten, bis sich dann der von Lavoisier geprägte Name «acide carbonique» einbürgerte, der nach Black «ungemein passend» sei.

Wesentlicher erscheinen uns seine Äußerungen über die grundsätzliche Neuorientierung der Chemie in erkenntnismäßiger und technischer Hinsicht. Mit berechtigtem Hochgefühl läßt er seine Zuhörer wissen: «Die Grenzen der Chemie sind wunderbar erweitert worden, und man hat die unerwartetsten Entdeckungen gemacht», wobei er an die Zusammensetzung des Wassers «aus zwei Luftarten» und des Diamanten aus reinem Kohlenstoff denkt. Unglaublich sind nach Black auch die technischen Verbesserungen, denn «bei dem Verfolg dieser Untersuchungen wurde der chemische Apparat sehr verbessert, und wir behandeln diese schlüpfrigen (!) Substanzen wie vorher feste Körper und Flüssigkeiten in unsern gewöhnlichen Gefäßen» (Vorlesungen II, S. 398); ein Fortschritt, der sich nicht zuletzt an den Namen des bisher so wenig bekannten Macbride knüpft. Black würdigt dann ziemlich eingehend die Verdienste der nach ihm auf dem Gebiet der Gase arbeitenden Chemiker, an erster Stelle natürlich seinen Schüler Henry Cavendish (1731-1810), dann Priestley, Scheele und vor allem Lavoisier.

Damit sind wir bei der wichtigsten Frage angelangt, wie sich die beiden kongenialen Männer zueinander gestellt haben. Im Lichte der Biographie Robisons, der allerdings persönlichen Umgang mit Black pflegte, hatte es den Anschein, als wäre dieser auf den jüngeren Reformator der Chemie eher schlecht zu sprechen gewesen. Eines dürfte sich aus dem bereits Gesagten ergeben haben: Die großen Leistungen der französischen Forscher und die Umformung der gesamten chemischen Vorstellungen, die sich aus ihren Arbeiten ergab, wurden vom alternden Black schon relativ früh vollauf anerkannt. Diese Feststellung schließt auch sein Verhältnis zur Phlogistontheorie in sich, mit der er für sich selber weit früher, als dies wohl in seinen Vorlesungen zum Ausdruck kam, gebrochen hatte. 
Kendall hat in seiner eingangs erwähnten Arbeit auf Grund der von uns nicht eingesehenen Archivstudien McKies einwandfrei festgestellt, daß Black sich zu Lavoisier auch persönlich nicht nur korrekt, sondern sehr positiv eingestellt hat. $\mathrm{Ja}$, er war, wie sein Brief vom 28. Dezember 1790 erkennen läßt, von Bewunderung erfüllt für die Entdeckungen des französischen Fachgenossen. Die Veröffentlichung von Blacks Urteil über die Phlogistonlehre in seinem ersten bekannten Brief an Lavoisier (24. Oktober 1790) geschah mit dessen vollkommenem Einverständnis, wie diese jüngsten, im deutschen Sprachgebiet wenig bekannten Nachforschungen ergeben haben. In diesem Sinn müßte auch die Feststellung von Speter (l. c., S. 251) korrigiert werden. Zu dem Bild unveränderlicher Ruhe und stoischen Gleichmuts, die in der biographischen Skizze hervorgehoben wurden, paßt nun auch diese Haltung gegenüber dem charakterlich nicht ganz einwandfreien Lavoisier weit besser, als die Auffassung Robisons, der Black als eher kleinlichen Geist hingestellt hatte.

Wie bereits erwähnt wurde, verfolgte Black auch die Anwendung der «fixen Luft» zu therapeutischen Zwecken mit reger Aufmerksamkeit, ohne allerdings die Übertreibungen gewisser Heißsporne mitzumachen. Dies gibt besonders in bezug auf die auflösende Wirkung der kohlensäurehaltigen Wässer, von der er kurz und bündig feststellte: «Sichere Auflösungsmittel kenne ich nicht», eine Auffassung, die mit derjenigen der kritischen Ärzte aller Jahrhunderte übereinstimmt. Hingegen ließ er die erfrischende und kühlende Wirkung bei Magenstörungen und wohl auch die heilende Kraft der «fixen Luft» bei «Lungenauszehrung» gelten (Vorlesungen II., 391 ff.). Die eigentliche Ära der Pneumatotherapie, wie sie im Gefolge von Priestley, Lavoisier, Davy u.a. einsetzte, erlebte Black nicht mehr. Auch hier hätte wahrscheinlich sein maßvolles Urteil von gewissen Übertreibungen abgehalten.

\section{Literaturverzeichnis}

\section{Darstellungen}

H. GuerLac, The Continental Reputation of Stephen Hales, in Arch.Internat. Hist. Scienc. (Archeion) 4. (1951) 405-12.

James Kendald, The First Chemical Society, The First Chemical Journal, and the Chemical Revolution, in Proceed.Roy. Soc. Edinburgh. Sect. A., Vol. 63 (1952) 346-58.

Milton Kerker, Herman Boerhaave and the Development of Pneumatic Chemistry, in Isis 46 (1955) 36-49. 
Hermann Kopp, Geschichte der Chemie, 1. Theil, Braunschweig 1843; 3. Theil, 1845.

A.L.Lavorsier, Opuscules physiques et chymiques, 1774, in CEuvres, Tom. I, Paris 1864.

Douglas McKie und Niels H. De V. Heathcote, The Discovery of Specific and Latent Heats, London 1935.

Douglas McKie, On Thos. Cochranes MS. Notes of Blacks Chemical Lecture, 1767-8, in Annals of Science 1 (1936) 101-10.

- Antoine Lavoisier, New York (Schumann) 1952.

Hélène Metzger, Newton, Stahl, Boerhaave et la doctrine chimique, Paris 1930.

Ernst von Meyer, Geschichte der Chemie, 4. Auflage, Leipzig 1914.

Sir William Ramsay, Joseph Black, M.D., in Beiträge zur Geschichte der Chemie, dem Gedächtnis von Georg W.A. Kahlbaum gewidmet, Leipzig/Wien 1909.

Max Speter, Black, in G.Bugge, Das Buch der großen Chemiker, Bd. I, Weinheim 1929. Unveränderter Nachdruck 1955.

Arthur Tröndle, Geschichte des Atmungs- und Ernährungsproblems bei den Pflanzen, Zürich und Leipzig 1925.

Paul Walden, Maß, Zahl und Gewicht in der Chemie der Vergangenheit, Stuttgart 1931.

- Geschichte der Chemie, Bonn 1947.

- Chronologische Übersichtstabellen zur Geschichte der Chemie, Berlin/Göttingen/Heidelberg 1952.

$$
\text { II. Quellen }
$$

Auserlesene kleine Werke dreyer berühmter Englischer Chymisten, Kopenhagen und Leipzig 1774.

Joseph Black, Experiments upon Magnesia alba, Quicklime, and Some Other Alcaline Substances. Essays and Observations, Physical and Literary, Vol. II. Edinburgh 1756, S.157-225. (Dasselbe separat, Edinburgh 1777.)

- Vorlesungen über die Grundlehren der Chemie. 3 Bände, Hamburg 1804.

Joh. Christ. Polykarp Erxleben, Physikalisch-chemische Abhandlungen, erster Band, Leipzig 1776.

Stephen Hales, Statical Essays Containing Vegetable Staticks, 2 Bände, 3. Auflage, London 1738.

Joh. Bapt. van Helmont, Ortus Medicinae, Amsterdam 1648.

David Macbride, Experimental Essays on Medical and Philosophical Subjects, 2. Auflage, London (A. Millar und T. Cadell) 1767.

Johann Pringle's Beobachtungen über die Krankheiten einer Armee. Übersetzung von Lic. Johann Ernst Greding. Altenburg 1754. 